\title{
Air Exchange Rate and Internal Air Flows in a Naturally Ventilated Museum Building
}

\author{
Mikael Björling ${ }^{1 *}$, and Guro Hjulstad ${ }^{2}$ \\ ${ }^{1}$ Department of Electrical Engineering, Mathematics and Science, Faculty of Engineering and Sustainable Development, University \\ of Gävle, Sweden \\ ${ }^{2}$ Department of Collection Management, Museum of Cultural History, University of Oslo, Norway
}

\begin{abstract}
A controlled indoor environment is crucial to the preservation of valuable historical artefacts in museums, but is influenced by many factors such as building properties, exhibit design, number of visitors, outdoor conditions etc. This study aims to monitor the local air exchange rates (AERs) and internal air flows in the Viking Ship Museum, Oslo, Norway during different outdoor conditions and is part of a project to create a new museum for the ships. Homogeneous emission tracer techniques (with tracer A) were used to monitor the local mean age of air (from which the local AER can be estimated). The internal air flows from a building zone were monitored by loading that zone with another tracer (B). The building outline is in the shape of a cross with four wings emanating from a central tower and thus naturally creates five zones to investigate. Three measurement periods were conducted with outdoor conditions ranging from winter to late summer. During winter conditions the average hourly air exchange rate $(\mathrm{ACH})$ for the museum is fairly low $\left(0.05 \mathrm{~h}^{-1}\right)$, but during summer conditions it rises fourfold $\left(0.2 \mathrm{~h}^{-1}\right)$. During the summer, windows and doors may be kept open and the number of visitors peaks. The internal flows are very large, as indicated by very similar patterns of the sampler loads for both A and B tracers in relation to the twenty sampling positions.
\end{abstract}

\section{Introduction}

The Viking Ship Museum in Oslo houses three of the world's best preserved Viking ships from the $9^{\text {th }}$ century A.D.: Gokstad, Oseberg and Tune, as well as several artefacts found during their excavations. This study aims to characterize the conditions of the indoor environment (particularly the inflow of outside air and the inter-zonal flows) of the present museum building and is part of a project to construct a new adjacent museum for the ships. Studies over a longer periods of time of large and naturally ventilated buildings are rare and therefore of general interest.

\section{Materials and methods}

Ventilation measurements are challenging in terms of the sheer size of the naturally ventilated museum building and its layout reminiscent of church (see Figure 1 for a floor plan and zone labels). The building consists of a central square tower (A) with a ceiling height of 20.4 meters (m). Four wings (B-E) are emanating at right angles from the tower zone via valves with ceiling height $7.7 \mathrm{~m}$. The ceiling construction differs in different parts of the museum as illustrated in the photographs in Figure 2. The ship's wings (B-D) have valve shaped ceilings with a height of $9.0 \mathrm{~m}$ (see Figure 2, left and middle), whereas the Gjenstand (Artefact) room (E) has a flat ceiling with a middle height of $8.2 \mathrm{~m}$ and $3 \mathrm{~m}$ on each side (see Figure 2, right). In the
Vestibule (Entrance Hall) the ceiling follows the saddle roof with height $9 \mathrm{~m}$ and it is separated from the Gokstad wing (D) by a valve with ceiling height $7.7 \mathrm{~m}$ (see Figure 2, left).

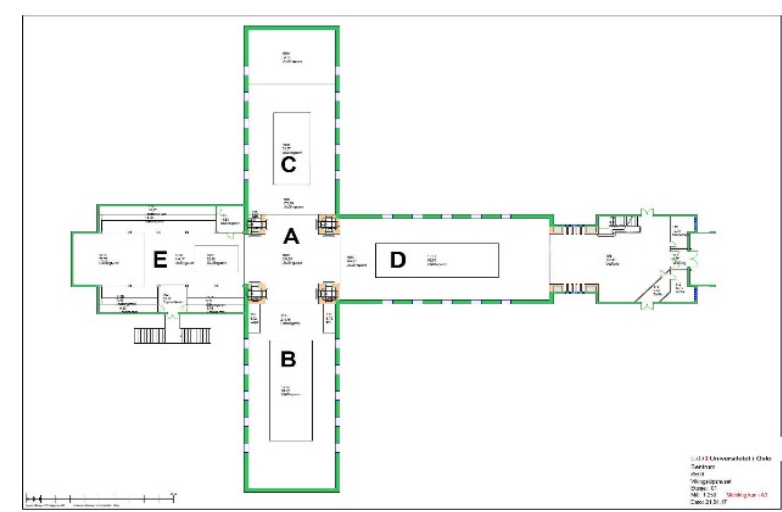

Figure 1. Plan of the Viking Ship Museum with zone labels. $\mathrm{A}$ is the tower zone, $\mathrm{B}$ is the Gokstad wing, $\mathrm{C}$ is the Tune wing, $\mathrm{D}$ is the Oseberg wing, $\mathrm{E}$ is the Gjenstand (Artefact) room, and to the right is the Vestibule (Entrance Hall). The scale in the lower left corner is 20 meters. Zone E points in a northwest direction. Drawing courtesy of University of Oslo.

The average local mean age of air was measured using the homogeneous emission tracer gas technique described in NORDTEST Standard VVS 118 [1] and ISO 16000-8 [2]. The underlying multi-zone approximation of buildings is described in Etheridge

\footnotetext{
* Corresponding author: mikael.bjorling $@$ hig.se
} 
and Sandberg [3]. In order to achieve homogeneous emission, a large number (293) of PFT tracer sources (A, perfluorobenzene) were evenly distributed in the building on strings attached to the ceilings.

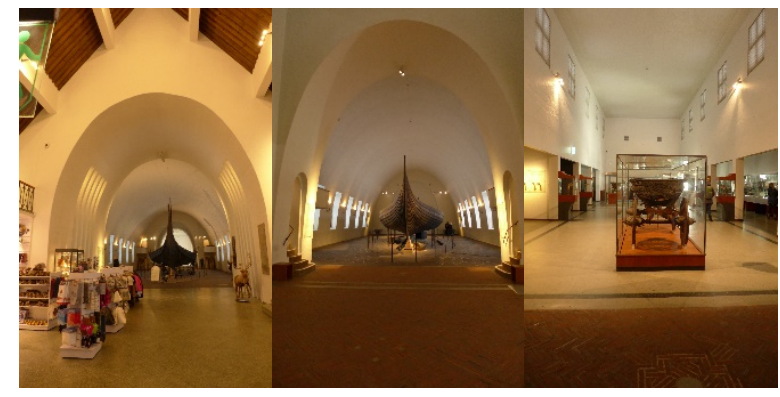

Figure 2. Plan of the Viking Ship Museum with zone labels. $\mathrm{A}$ is the Tower zone, $\mathrm{B}$ is the Gokstad wing, $\mathrm{C}$ is the Tune wing, $\mathrm{D}$ is the Oseberg wing, $\mathrm{E}$ is the Gjenstand (Artefact) room, and to the right is the Vestibule (Entrance Hall). Drawing courtesy of University of Oslo.

Passive collection onto charcoal tubes, analysed by GC, were used for long term averages [4]-[9]. Samplers were suspended on strings attached to the ceilings to sample different heights in twenty sampling points in the building (four each in Zones $\mathrm{A}-\mathrm{C}$ and $\mathrm{E}$, three in Zone $\mathrm{D}$ and one in the Vestibule zone). The location of the samplers and the labels are listed in Table 1.

Table 1. Sampler locations and labels. The location numbers will be used in the figures in the Results for brevity.

\begin{tabular}{|c|c|c|c|c|}
\hline Zone & $\begin{array}{c}\text { Height } \\
{[\mathrm{m}]}\end{array}$ & $\begin{array}{c}\text { Distance } \\
\text { from } \\
\text { Tower } \\
{[\mathrm{m}]}\end{array}$ & No. & $\begin{array}{c}\text { Location } \\
\text { Label }\end{array}$ \\
\hline A & 1.8 & 0 & 1 & Tower_P \\
A & 13 & 0 & 2 & Tower_H1P \\
A & 16 & 0 & 3 & Tower_H2P \\
A & 19 & 0 & 4 & Tower_H3P \\
\hline B & 1.5 & 20 & 5 & Gokstad_P \\
B & 8 & 20 & 6 & Gokstad_HP \\
B & 1.5 & 5 & 7 & Gokstad_P_nt \\
B & 8 & 5 & 8 & Gokstad_HP_nt \\
\hline C & 1.5 & 20 & 9 & Tune_P \\
C & 8 & 20 & 10 & Tune_HP \\
C & 1.5 & 5 & 11 & Tune_P_nt \\
C & 8 & 5 & 12 & Tune_HP_nt \\
\hline D & 1.5 & 20 & 13 & Oseberg_P \\
D & 8 & 20 & 14 & Oseberg_HP \\
D & 1.5 & 5 & 15 & Oseberg_P_nt \\
\hline Entrance & 1.5 & 40 & 16 & Vestibule_P \\
Hall & & & & \\
\hline E & 1.8 & 15 & 17 & Gjenstand_P \\
E & 7.2 & 15 & 18 & Gjenstand_HP \\
E & 1.5 & 5 & 19 & Gjenstand_P_nt \\
E & 7.2 & 5 & 20 & Gjenstand_HP_nt \\
\hline & & & &
\end{tabular}

The samplers in the tower (Zone A) are distributed along a string from the bottom $(1.8 \mathrm{~m}$, Tower_P $)$ to the top $(19 \mathrm{~m}$, Tower_H3P) of the tower. The samplers with the labels "P" and "HP" in the other zones are placed at breathing height and near the roof, respectively. In each of the zones B-E, there are two sampler strings placed along the axis of each zone: one string is placed nearer the central tower ("nt") and the other at the opposite side of the zone. In the Entrance Hall there is only one sampler (Vestibule_P). The temperature and relative humidity was logged by the museums stationary BLD9010 Hygrotrac sensors in Zones B-E, a HOBO mx1101 Data logger in Zone A, and a Hanwell ml4106 Data logger in the Entrance Hall.

In order to trace inter-zonal flows, a second type of PFT tracer (B, perfluorotoluene) was homogeneously emitted in a selected single zone, one for each measurement (except for the Vestibule zone). Three measurement periods were conducted with outdoor conditions ranging from winter to late summer. Period 1 and 2 consisted of five separate weekly measurements. On day one, the B sources were moved from one zone to the next zone (in the order: A, B, E, D, C). After an equilibration period of three days, samplers were placed in all sampling positions and then passive sampling followed during day four to eight (day one for the next measurement). The third and last period only investigated three zones (A, B, E).

The average local air exchange rates (AER) are estimated as the inverse of the average of the the local mean age of air. The hourly air exchange rate $(\mathrm{ACH})$ for the whole museum building is calculated as the volume weighted average of the local AERs. Each zone is assumed to be completely mixed and the Zone AERs contributes to the estimate in proportion to the zone volumes [3].

\section{Results}

\subsection{Temperature and relative humidity}

Each of the thirteen separate measurements reflect the indoor conditions in the Viking Ship Museum with the outdoor environment ranging from early spring to early autumn. In Table 2, the average indoor temperature and relative humidity during each measurement is listed. For further clarity of the measurement sequence, the Zone in which B-tracer was emitted is also given.

Table 2. Average indoor temperature $(t)$ and relative humidity (RH) with the corresponding standard deviation (SD), as well as B tracer location for each measurement. The date corresponds to the start of the measurement period.

\begin{tabular}{|c|c|c|c|}
\hline $\begin{array}{c}\text { Start } \\
\text { Date }\end{array}$ & $\begin{array}{c}\mathrm{B} \text { in } \\
\text { Zone }\end{array}$ & $\begin{array}{c}t\left[{ }^{\circ} \mathrm{C}\right] \\
(\text { Mean } \pm \text { SD })\end{array}$ & $\begin{array}{c}\mathrm{RH}[\%] \\
(\text { Mean } \pm \text { SD) }\end{array}$ \\
\hline 5-Mar & A & $14.5 \pm 0.9$ & $43.8 \pm 3.0$ \\
12-Mar & B & $15.7 \pm 0.8$ & $44.3 \pm 3.5$ \\
19-Mar & E & $15.9 \pm 0.8$ & $40.5 \pm 3.2$ \\
26-Mar & D & $16.7 \pm 0.8$ & $39.4 \pm 3.9$ \\
6-Apr & C & $17.2 \pm 0.7$ & $45.9 \pm 2.9$ \\
\hline 16-Apr & A & $19.3 \pm 0.5$ & $50.1 \pm 2.1$ \\
23-Apr & B & $19.3 \pm 0.5$ & $48.5 \pm 2.2$ \\
30-Apr & E & $18.6 \pm 0.4$ & $53.8 \pm 1.8$ \\
7-May & D & $19.2 \pm 0.3$ & $57.4 \pm 1.7$ \\
18-May & C & $22.1 \pm 0.3$ & $48.2 \pm 2.1$ \\
\hline 28-Aug & A & $20.6 \pm 0.2$ & $61.8 \pm 2.2$ \\
3-Sep & B & $21.2 \pm 0.2$ & $62.8 \pm 1.6$ \\
10-Sep & E & $19.3 \pm 0.7$ & $60.8 \pm 3.2$ \\
\hline
\end{tabular}


The standard deviations (SD) of the temperature are higher during cooler outdoor conditions than during the warmer period when windows may be opened. This indicates that the temperatures are more uniform and that the air exchanges between zones are larger during the warmer period. For all measurements, the Tune wing (Zone C) is consistently the coolest zone and the Artefact Room (Zone E) is the warmest zone (or among the warmest zones).

\subsection{Total hourly air exchange rate}

In Figure 3, the estimated hourly air exchange rates $(\mathrm{ACH})$ for the whole museum building are presented. During early spring to mid-May (winter conditions) the $\mathrm{ACH}$ in the museum is fairly low $0.061 \pm 0.006 \mathrm{~h}^{-1}$ (SD). From mid-May it is permitted to keep windows and doors open during opening hours. This is clearly noticeable in Figure 3. The ACH is a factor three to four larger from mid-May to early autumn (summer conditions) $0.18 \pm 0.02 \mathrm{~h}^{-1}$ (SD).

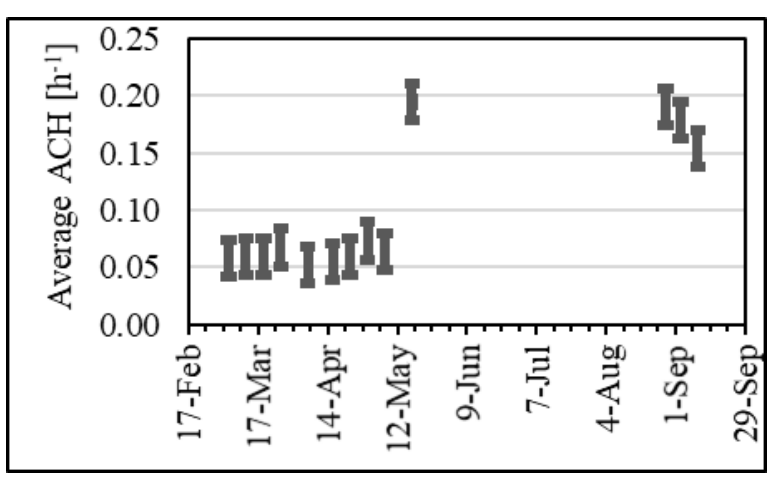

Figure 3. Estimated ACH for the whole Viking Ship Museum for the thirteen measurement periods performed from March 5 to September 18, 2018. The placement of the point, in reference to the time-axis, represents the start date of the measurement period. The ranges approximate the $95 \%$ confidence limits.

\subsection{Local air exchange rates}

In Figure 4, the local AER in each of the twenty sampling points are presented for the two different categories of high and low ACH (represented by the measurements starting at March 5 and August 28, respectively). During the period with low ACH (Figure 4a), the local AERs are fairly uniform, close to the ACH, with a weak tendency to be lower in the sampling positions in the tower (Zone A, 2-4) and slightly higher in the Entrance Hall (16) and the nearby Zone D (1315). In Zone B, the AER near the roof and the tower (8) is closer to the AERs in Zone A (1-4) and lower than the other AERs in Zone B (5-7). In Zones $\mathrm{C}$ and $\mathrm{E}$, the AERs in the lower sampling positions farthest from the tower ( 9 and 17, respectively) tend to be lower than the other AERs in the same zone (10-12 and 18-20, respectively).

During the period with higher ACH (Figure 4b), the variation of local AERs is higher and larger differences between the lower and higher sampling positions are observed. In Zone A, the AERs in the higher positions (3-4) are smaller than in the lower positions (1-2), where the latter AERs are very close to ACH. The AERs in the Entrance Hall (16) and the nearby Zone D (1315) are clearly above ACH. In Zone D, the AER in the higher position farthest from the tower (14) is markedly larger than the AER in the lower position (13). In Zones $\mathrm{B}$ and $\mathrm{C}$, the AER in the lower positions farthest from the tower (5 and 9, respectively) are markedly larger than the AERs in the other sampling positions in the zone (6-8 and 9-12, respectively). In Zone E, the AERs are close to $\mathrm{ACH}$ and slightly smaller in the lower positions (17 and 19) than in the higher positions (18 and $20)$. The other measurements show similar trends in each of the two categories: low or high $\mathrm{ACH}$.

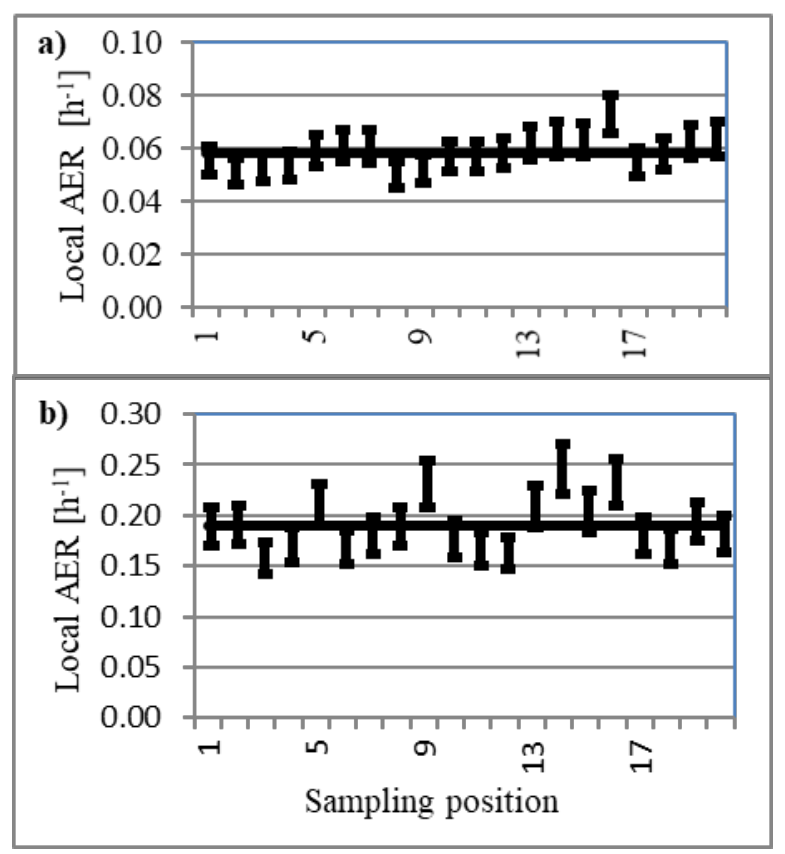

Figure 4. The estimated local AER in all sampling positions for the measurement period starting March 5 (a) and August 28 (b). The ranges approximate the $95 \%$ confidence limits and the solid line is the average $\mathrm{ACH}$ for the measurement.

\subsection{Inter-zonal air flows}

In this study, the air in a single zone $\mathrm{X}$ is tagged with a second tracer (B). In addition, the tracer A is emitted homogeneously in all zones in order to evaluate the local AERs. Then it should be theoretically possible to calculate the inter-zonal air flows between zone $\mathrm{X}$ and (a singly connected) zone $\mathrm{Y}$ and the direct inflow of outside "fresh" air into zone $\mathrm{X}$ by applying mass balances Unfortunately, huge relative errors rendered these calculations meaningless. However, some qualitative information can be gleaned from the relative sampler loads. Figure 5 show the sampler loads for tracer A and B in all sample positions for a case of low $\mathrm{ACH}$ (start date March 5). Even though the B tracer is emitted locally in the tower (Zone A), it is present in all zones with concentrations that are comparable to those in found in the tower (see Figure 5b). This indicates a 
presence of large internal air flows between all zones. Furthermore, the pattern of B sampler loads in the sampling positions (shown in Figure 5b) closely resembles the pattern of A sampler loads in Figure 5a. Since a low sampler load of A corresponds to a high local AER, and vice versa, this indicates that the sampler loads of B are more determined by the local AER rather than by the zone of origin.

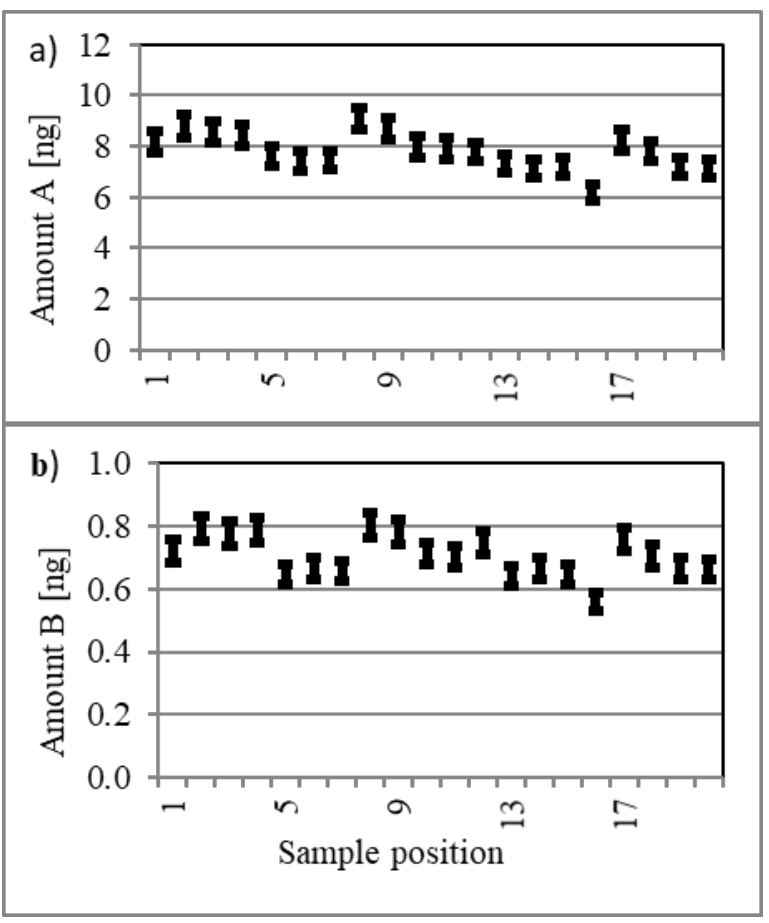

Figure 5. Local sampler loads for all sampler positions in the measurement period starting at March 5 when the B tracer is emitted only in the tower (Zone A). The ranges approximate the $95 \%$ confidence limits.

Furthermore, the same observations appear to be valid when the B tracer is emitted in another zone. This is exemplified by the measured sampler loads when the $\mathrm{B}$ tracer is emitted in Zone B as shown in Figure 6. Only minor discrepancies are observed in Zone B (5-8) and in Zone C (9-12).

When $\mathrm{ACH}$ is high, a larger variation of the local AERs was observed in Figure $4 b$, as compared to the case of lower ACH in Figure 4a. Thus, a correspondingly larger variation of the sampler loads is expected for the cases of high $\mathrm{ACH}$ as compared to those with lower $\mathrm{ACH}$. In the measurements presented in Figure 7 the $\mathrm{B}$ tracer is emitted in the tower (Zone A), as in Figure 5, but the $\mathrm{ACH}$ is higher. According to expectations, the sampler loads in Figure 7 vary more than in Figure 5. Nevertheless, the same general observations are supported: tracer B is found in all zones in comparable concentrations indicating large air flows between zones; the pattern of sampler loads of tracer B in the sampling positions closely resembles that of the sampler loads of tracer A demonstrating that the sampler loads of B are more determined by the local AER than by the zone of origin. Minor divergences are observed, for example in Zone E (17-20).
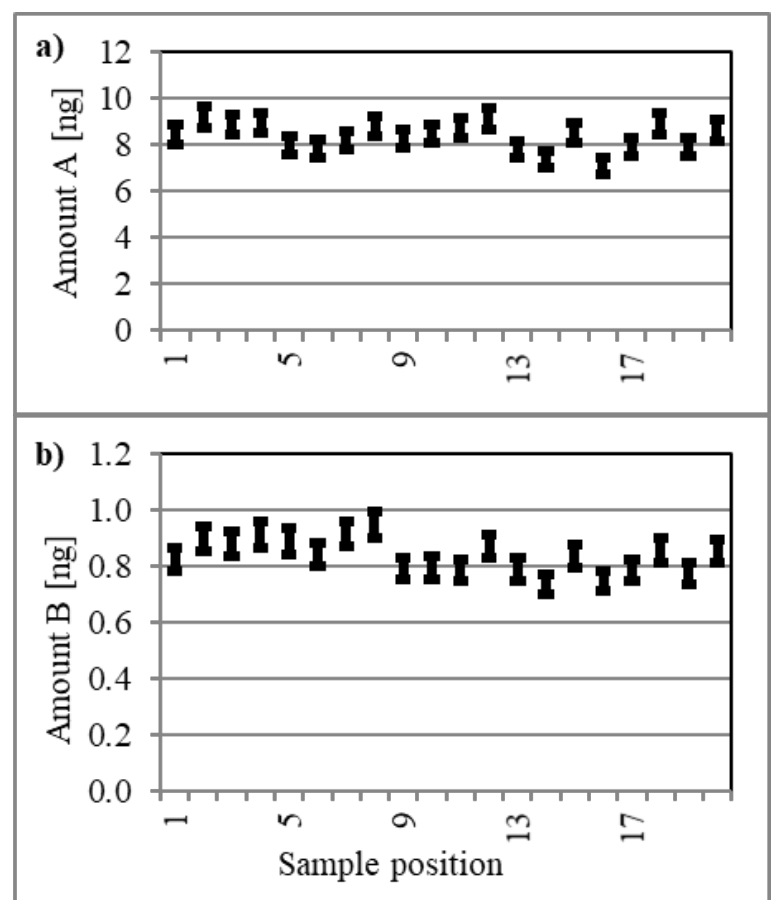

Figure 6. Local sampler loads for all sampler positions in the measurement period starting at March 12 when the B tracer is emitted only in the Zone B. The ranges approximate the $95 \%$ confidence limits.
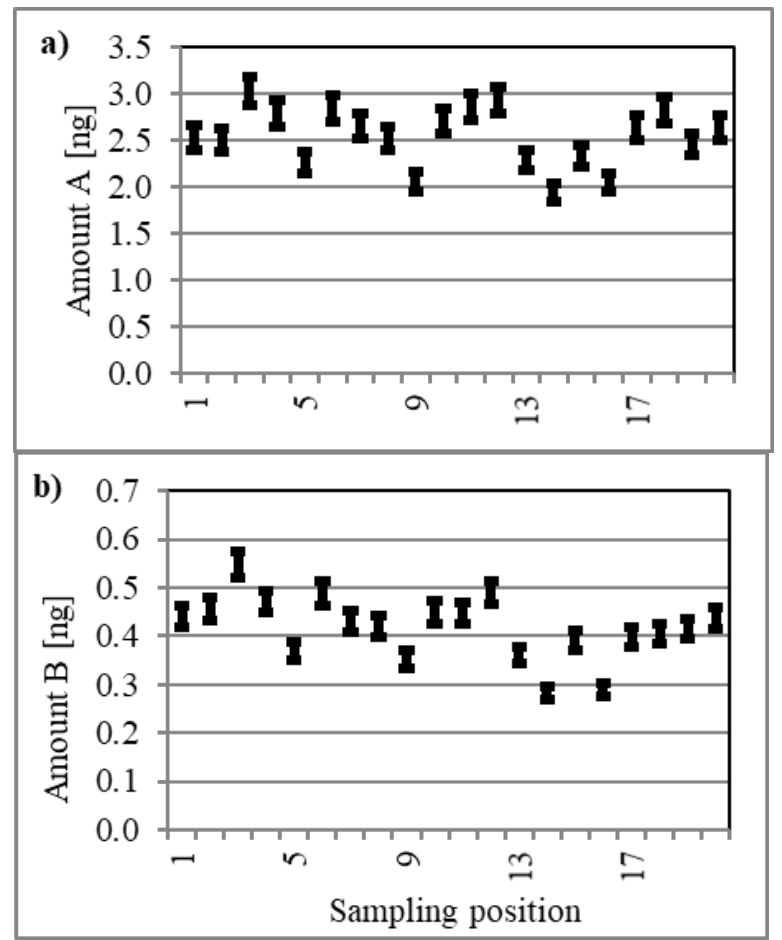

Figure 7. Local sampler loads for all sampler positions in the measurement period starting at August 28 when the B tracer is emitted only in the tower (Zone A). The ranges approximate the $95 \%$ confidence limits.

For comparison, the sampler loads with high $\mathrm{ACH}$ and $\mathrm{B}$ tracer emitted in Zone B, as in Figure 6, are shown in Figure 8. The same general observations, as before, are supported for all zones, except Zone B. The B 
sampler loads for the lower sampling positions (5 and 7) are markedly larger than the sampler loads for the higher sampling positions (6 and 8). The pattern for the A sampler loads for the corresponding sampling positions do not display these large differences. In addition, the markedly lower A sampler load in the sampling position farthest away from the tower (5) observed in Figure 7 is absent in Figure 8. This may be attributable to an openable window in Zone B (see Discussion).
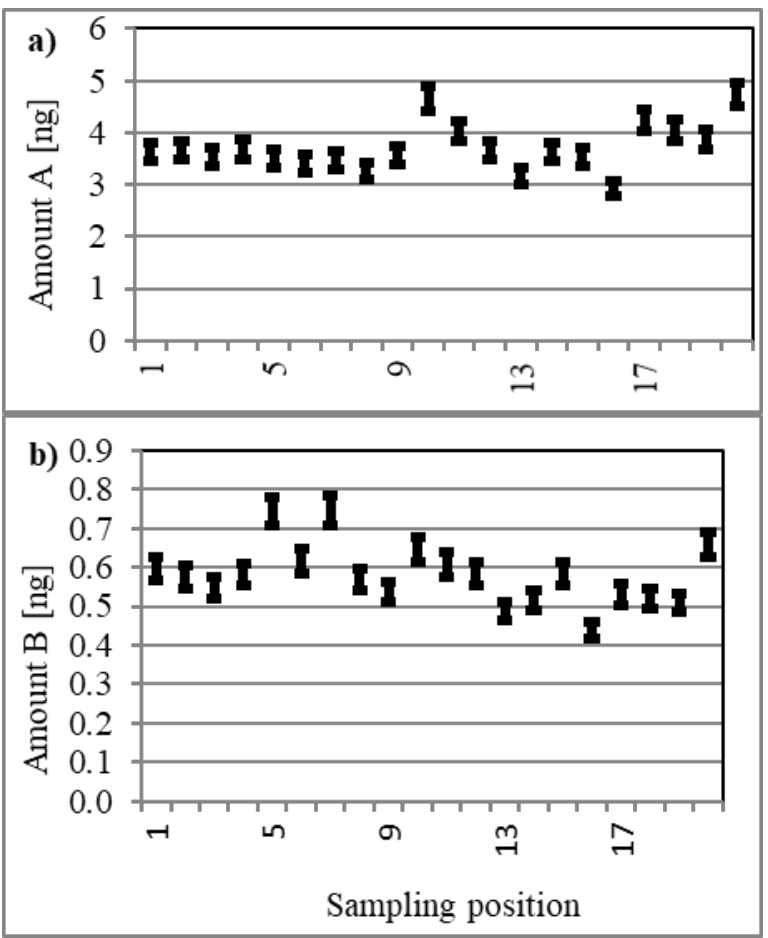

Figure 8. Local sampler loads for all sampler positions in the measurement period starting at September 3 when the B tracer is emitted only in the Zone B. The ranges approximate the $95 \%$ confidence limits.

\section{Discussion}

One of the aims of this study is to characterize the indoor conditions of the Viking Ship Museum during a longer time period that includes both the heating and summer season. This aim is accomplished since the thirteen measurements are conducted over a wide range of outdoor temperatures and wind conditions from the beginning of March to mid-September. During the measurement period the average indoor temperatures range from 14 to $22{ }^{\circ} \mathrm{C}$. The relative humidity ranges from 39 to $63 \%$. Zone $\mathrm{C}$ is the coolest region throughout the measurement period. This cannot be explained by the tower shading the solar radiation since Zone E (the warmest region) ought to be equally shaded by the tower. The likely explanation is that the effect of solar warming is limited because Zone $\mathrm{C}$ is frequently blacked out for multimedia presentations. Why Zone $\mathrm{E}$ is the warmest region is less clear.

The second aim was to quantify the infiltration of outdoor air into each zone and to map the inter-zonal flows. The former part is partly fulfilled by determining the local air exchange rates (AERs) in twenty selected sampling positions and by estimating the hourly air exchange rate $(\mathrm{ACH})$ for the whole museum as the volume weighted average of the local AERs. The local AER quantifies the distribution of incoming outdoor air to the local environment of the sampling position. A high local AER signifies that the tracer concentration in the local environment is amply diluted by the unlabelled "fresh" outdoor air. This situation corresponds to a younger local mean age of air. The opposite case of an older local mean age of air means that the air in the local environment of the sampling position has spent a longer time within the building and is less diluted by younger outdoor air. Thus, this case corresponds to a lower local AER. The same logic obviously applies to ACH.

The measured ACHs of the Viking Ship Museum are slightly lower than those measured in other large and naturally ventilated buildings such as older churches (see for example [10-11]). This is probably due to a more air-tight building envelope as compared to churches. A recent change to modern security windows may have contributed to an increased air-tightness of the museum envelope.

On the other hand, a lower AER (and ACH) may also be due to a difference between the ventilation conditions in the museum during visiting hours and when it is closed. It is expected that the AERs are lower during visiting hours than during the periods when the museum is closed As discussed previously ([12-13]), periods with low ventilation (when tracer concentrations are high) may dominate the passive sampler loads. While the average of the local mean ages of air are correctly estimated for both conditions, the average of the inverses (i.e. the AERs) are not. The average $\mathrm{ACH}$ estimates over both conditions are, more or less, biased towards the average AERs in the periods of low ventilation. A critical suspicion should be aroused that the measured AERs could be more indicative of the closing period than of the visiting hours. The observed large differences in the AERs between measurements, that appear to be explained by user intervention during visiting hours, suggest that these interpretation problems are less severe in this study.

As mentioned above, the direct infiltration of air into each zone and the inter-zonal flows could not be quantitatively determined. The local AER quantifies the relative access to outdoor air in a sampling position, but cannot resolve where this outdoor air comes from. The purpose of adding a second tracer B to a single zone was to solve this problem. While every mass balance calculations yield results, a subsequent error analysis shows that the estimated errors are larger. This error sensitivity arises because the mass balances involve differences in $\mathrm{A}$ and $\mathrm{B}$ tracer concentrations between the zones. When the inter-zonal air flows are large, as observed in this study, these concentration differences are close to the accuracy of the chemical analysis and the relative errors become huge.

Fortunately, the measured local AERs as well as the $A$ and $B$ sampler loads allow some qualitative conclusions concerning the air flows in the museum. In a naturally ventilated building, air flows are caused by pressure differences that ultimately can be traced to two 
separate driving forces: wind or differences in air density [14]. The latter is often referred to as stack flow. One type of stack flow is generated by heat sources. Since the density of the air warmed by a heat source is lower than the density of the surrounding cooler air, more distant from the heat source, the warm air tends to move upwards. The rising warm air must be replaced by the cooler surrounding air that is subsequently heated and will to tend to rise. An air flow is generated. Apart from heating devices, the museum visitors themselves are important heat sources generating stack air flows.

Considering the museum architecture, the tower appears to be a natural exit for the rising air flows generated by heat sources. This can also be deduced from Figure 4, since the local AERs in the tower (1-4) are less than or equal to the average AER in the museum (i.e. ACH). The local mean age of exiting air due to stack flow is usually older than the average local mean age in the building [3].

On the other hand, the tower cannot solely be an exit of air flows from the museum. If that was the case, very little of the B tracer emitted in the tower would be present in the other zones. Instead the opposite is observed in Figures 5 and 7. This can only be explained by large air flows from Zone A to the other zones. These downward flows from the tower may either be due to wind pressure generated or to cooler and denser air sinking in the tower. The latter may even be caused by exiting and rising warmer air from the museum. The fact that the B tracer is distributed to all zones, regardless of which zone it is emitted in, implies that all zones are interconnected by large inter-zonal air flows. These air flows also seem to contribute to a good internal mixing of the air within each zone.

Very little stratification is observed. The lower and higher sampling positions show remarkably similar results, especially when the overall ACH is low (see Figure 4a). The highest local AER (16) for the measurement shown in Figure $4 \mathrm{a}$ also indicates that the largest proportion of outdoor air infiltrates into the Entrance Hall, as compared to the infiltration into the other zones. This larger intake of outdoor air also appears to affect the local AERs in the adjacent Zone D slightly.

In Figure 4b, some stratification is observed. The large local AER in the Entrance Hall (16) coupled with the equally large local AER in the high sampling position in Zone D (14) may indicate that the incoming outdoor air primarily takes the high route from the Entrance Hall, through Zone D towards the tower. This could be the case if the outdoor air is warmer than the indoor air. The larger local AER for the lower sampling position farthest from the tower in Zone B (5) could be explained if the window in that zone is kept open during visiting hours. Since the lower sampling position is more affected by the outdoor air entering through the window in Zone B, this may indicate that the outdoor air is instead cooler than the indoor air. Thus, another possibility for the former air flow is a reverse direction from the tower, via Zone D, to the Entrance Hall. The single high AER in the low sampling position farthest from the tower in Zone C (9) is more difficult to explain as there are no openable windows in this zone. Furthermore, since the local AERs for both high and low sampling positions near the tower $(10-11)$ are much smaller, the outdoor air can reach 9 only by fairly narrowly defined flows along the walls or at middle height between 10 and 11 .

The differences in the pattern of the A and B sampler loads in Zone B that are observed in Figure 8 are also difficult to explain. A speculation is that warm outdoor air entering from the window is forced upwards to dilute the concentration of $\mathrm{B}$ tracer in the higher sampling positions (6 and 8 ), leaving the lower sampling positions (5 and 7) less diluted. However, this is difficult to reconcile with the fact that the A sampler loads are not affected in a similar way.

\section{Conclusions}

The tracer methods used in this study provide some useful tools to assess (the sometimes complex) air flows into, and within, naturally ventilated buildings. It is demonstrated that homogeneous emission of a tracer (A) enables capturing local differences in AER, not only between zones in large multi-zone buildings but also within zones. The latter is particularly important in the Viking Ship Museum where the zones are large and not well separated. As a bonus, the $\mathrm{ACH}$ for the whole building may be evaluated as the volume weighted average of all the local AERs.

The presence of large inter-zonal air flows is qualitatively demonstrated using a second tracer (B) that is emitted locally. In principle, the tracer methods used in this study should also allow for quantification of the inter-zonal air flows via mass balance calculations. However, the presence of large inter-zonal flows also lead to fairly uniform concentrations of both tracers in all the zone. As the differences in tracer concentrations between zones approach the accuracy of the chemical analysis of the tracer sampler loads, the relative errors in the mass balance calculations become prohibitive.

Infiltration of air through the building envelope is small in comparison to the large air volumes within the building. During summer conditions, open doors and windows contribute to a fourfold increase in the hourly air exchange rate $(\mathrm{ACH})$ in the museum, as compared to cooler outdoor conditions.

University of Oslo and University of Gävle are acknowledged for providing financial resources.

\section{References}

[1] NORDTEST, "Ventilation: Local mean age of air - homogeneous emission technique". Nordtest Method: NT VVS 118, Nordtest Finland, 1997.

[2] ISO 16000-8, "Indoor Air - Part 8: Determination of local mean ages of air in buildings for characterizing ventilation conditions", International Organization for Standardization, 2007, Revised 2016. 
[3] D. Etheridge, and M. Sandberg, Building Ventilation - Theory and Measurement. John Wiley \& Sons, Chichester, U.K, 1996.

[4] R. N. Dietz, R. W. Goodrich, E. A. Cote, and R.F. Wieser, "Detailed description and performance of a passive perfluorocarbon tracer system for building ventilation and air change measurement." In Measured Air Leakage in Buildings (Edited by H R Treschel and P L Lagus), ASTM STP 904, pp 203-264, 1986.

[5] Säteri J. O. (editor), (1991) "Development of the PFT-method in the Nordic Countries" Swedish Council for Building Research, Document D9,1991.

[6] H. Stymne, and C.A. Boman, "Measurement of ventilation and air distribution using the homogeneous emission technique - A validation". Healthy Buildings '94, Proc. of the 3rd International Conference, vol. 2, pp 539544, Budapest, Hungary, 1994.

[7] L. Öie, H. Stymne, C. A. Boman, and V. Hellstrand, "The ventilation rate of 344 Oslo residences", Indoor Air, vol. 8, pp. 190-196, 1998.

[8] G. Emenius, M. Svartengren, J. Korsgaard, L. Nordvall, G. Pershagen, and M. Wickman, "Building characteristics, indoor air quality and recurrent wheezing in very young children (BAMSE)", Indoor Air, vol. 14, pp. 34- 42, 2004.

[9] C. G. Bornehag, J. Sundell J, L. HägerhedEngman, and T. Sigsgaard, "Association between ventilation rates in 390 Swedish homes and allergic symptoms in children", Indoor Air, vol. 15, pp. 275-280, 2005.

[10] M. Björling, C.A. Boman, H. Stymne, "The Indoor Climate of a Naturally Ventilated Church." Proceedings of Healthy Buildings 2009, Syracuse, NY, U.S.A., 2009.

[11] A. Hayati, M. Mattsson, and M. Sandberg, "Single-sided ventilation through external doors: Measurements and model evaluation in five historical churches", Energy and Buildings, vol. 141, pp. 114-124., 2017.

[12] W. H. Nazaroff, "What does 'average' mean for time-varying air-change rates?"

Proceedings of Healthy Buildings 2009, Syracuse, NY, U.S.A., 2009.

[13] M. Björling, J. Akander, J. Steen Englund, "On Measuring Air Infiltration Rates Using Tracer Gases in Buildings with Presence Controlled Mechanical Ventilation Systems" In Indoor Air 2016: The 14th International Conference of Indoor Air Quality and Climate, July 3-8 2016, Ghent, Belgium: Conference Proceedings / [ed] E. Van Kenhove, J. Laverge, P. De Vlieger, ISIAQ, no. 875, 2016.

[14] F. Allard, Natural Ventilation in Buildings: A Design Handbook, James \& James Ltd., London, 1998. 